\title{
Ku-band Transition with not Metalized Air- Vias between Microstrip Line and Substrate Integrated Waveguide
}

\author{
Farouk Grine , Mohamed Taoufik Benhabiles and Mohamed Lahdi Riabi \\ Laboratoire des électromagnétismes et télécommunication, Université de Constantine 1, Route d'Ain El Bey, \\ Constantine 25000, Algerie \\ Farouk Grine; faroukgrine@umc.edu.dz \\ Mohamed TaoufikBenhabiles: mt.benhabiles@umc.edu.dz \\ Mohamed LahdiRiabi:ml.riabi@yahoo.fr
}

\begin{abstract}
In this letter, a new transition between microstrip line and substrate integrated waveguide in $\mathrm{Ku}$-band frequency is proposed. This transition composed of one row of not metallized air-vias drilled on both sides of the microstrip line with taper end. The electromagnetic analysis is carried out using a commercial software tool. The presented transition achieves return losses better than $41 \mathrm{~dB}$ in Ku-band frequency $(12.4-18 G H z)$. In order to validate the simulated results of the proposed concept, a back-toback transition prototype is designed, fabricated and measured. The measured results demonstrate a minimum return loss of 29.05 $\mathrm{dB}$ and maximum insertion loss of $0.685 \mathrm{~dB}$ over the entire $\mathrm{Ku}$ band frequency.
\end{abstract}

Index Terms-Substrate Integrated Waveguide; Microstrip Line; Tapred Transition; Air-Vias

\section{INTRODUCTION}

The emerging technology of substrate integrated waveguide (SIW), a veritable paradigm, considering migration from metal walls waveguides to the planar technology. In its simplest form, its two cylinder rows between two metals plates which can confine the electromagnetic field. Since the microstrip line is very practical in many configurations, including active components connectivity, the trend is to merge it in the same substrate with SIW, geometrically irreconcilable structures. This requires the development of transitions, junctions and couplings, with high technical quality, and therefore implies performing a good calculation model. These transitions are very important for the matching of impedance and field between the SIW and planar circuits. D. Deslandes et al. proposed the first transition between microstrip and SIW with taper form [1]. H. Nam et al. proposed a transition microstrip-to-SIW in Ku-band frequency range [2], in this transition, the return loss is about $15 \mathrm{~dB}$ and bandwidth is $24 \%$. In the past years, several works about the transition between SIW and microstrip line or coplanar waveguide have been developed ([3-8]). In [9] another transition from microstrip-to-SIW is proposed. This transition are formed by placing two vias symmetrically at either side the microstrip taper, this vias and the SIW vias, have the same diameter. In Ku-band frequency, this transition gives return losses better than $35 \mathrm{~dB}$. 
Furthermore, in this letter, a new transition between microstrip line and SIW structure is introduced. This transition constructed by placing one row of not metallized air-vias on both sides of the microstrip line. In Ku-band frequency (12.4 to $18 \mathrm{GHz}$ ), the new transition has been studied in two different substrate and it gives return losses better than $41 \mathrm{~dB}$. In order to verify the proposed scheme a back-to-back transition was fabricated.

\section{MICROSTRIP TRANSITION}

The microstrip line is one of the most used transmission lines in the conception of microwave systems. The topology of the structure transition between microstrip line and substrate integrated waveguide is shown in figure 1.This transition has three main parameters: the length $l$ of the tapered form, $w$ is the width and $w_{0}$ is the initial width. $w_{0}$ must be calculated to obtain the desired characteristic impedance. This width is generally selected to achieve a characteristic impedance of $50 \Omega$ and we calculate the ratio $w_{0} / h$ by the following formula [10]:

$\frac{w_{0}}{h}=\left\{\begin{array}{c}\frac{8 e^{A}}{e^{2 A}-2} \text { for } \frac{w_{0}}{h}<2 \\ \frac{2}{\pi}[B-1-\ln (2 B-1) \\ \left.+\frac{\varepsilon_{r}-1}{2 \varepsilon_{r}}\left\{\ln (B-1)+0.39-\frac{0.61}{\varepsilon_{r}}\right\}\right] \text { for } \frac{w_{0}}{h}>2\end{array}\right.$

$A=\frac{z_{0}}{60} \sqrt{\frac{\varepsilon_{r}+1}{2}}+\frac{\varepsilon_{r}-1}{\varepsilon_{r}+1}\left(0.23+\frac{0.11}{\varepsilon_{r}}\right)$

$B=\frac{377 \pi}{2 Z_{0} \sqrt{\varepsilon_{r}}}$

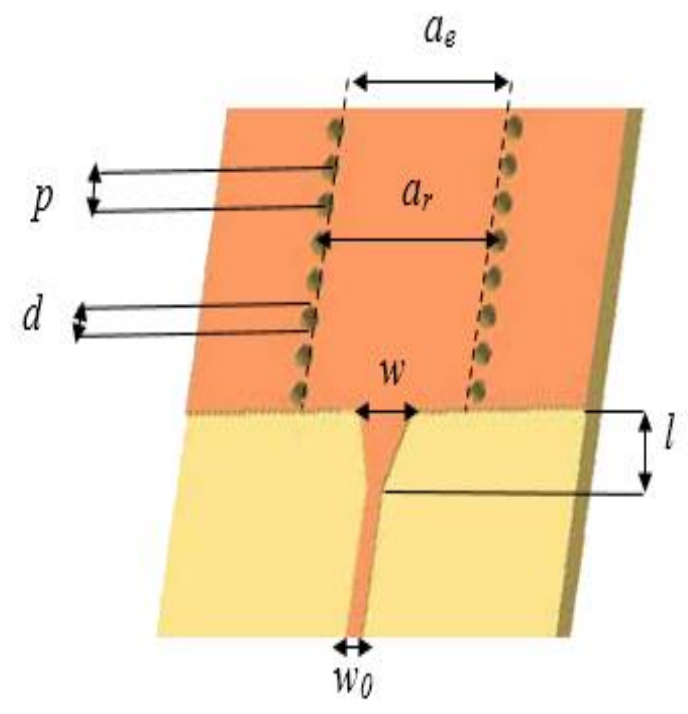

Fig. 1. tapered transition between microstrip line and SIW 
Thus, as " $h$ " is the substrate height, it becomes easy to calculate the value of $w_{0}$. It remains now the value of two other transition parameters to calculate. The $w$ must be calculated by equating the two right sides of the equations (4) and (5) and solving it ( $w_{e}$ is the width of an equivalent waveguide) [11]:

$$
\begin{aligned}
& \frac{1}{w_{e}}=\left\{\begin{array}{c}
\frac{60}{\eta h} \ln \left(8 \frac{h}{w}+0.25 \frac{w}{h}\right) \\
\frac{120 \pi}{\eta h\left[\frac{w}{h}+1.393+0.667 \ln \left(\frac{w}{h}+1.444\right)\right.}
\end{array}\right. \\
& \frac{1}{w_{e}}=\frac{4.38}{a_{e}} e^{-0.627 \frac{\varepsilon_{r}}{\frac{\varepsilon_{r}+1}{2}+\frac{\varepsilon_{r}-1}{2} \sqrt{1+12 \frac{h}{w}}}}
\end{aligned}
$$

For the parameter $l$ we can use a simpler method by choosing the median width between the microstrip line and the end of the transition, as follow:

$w_{\text {median }}=\left(w+w_{0}\right) / 2$

It suffices to calculate the wavelength for this width and set the length to aquarter of wavelength. We must first find the effective dielectric constant for this microstrip line width [11]:

$$
\varepsilon_{e}=\frac{\varepsilon_{r}+1}{2}-\frac{\varepsilon_{r}-1}{2} \frac{1}{\sqrt{1+12 \frac{h}{w_{\text {mediam }}}}}
$$

We must then calculate $\lambda_{\mathrm{c}}$ with the following equation:

$$
\lambda_{c}=\frac{1}{f_{c} \sqrt{\mu_{0} \varepsilon_{0} \varepsilon_{r}}}
$$

\section{PROPOSED TRANSITION STRUCTURE AND DESIGN}

The new transition we propose is achieved by drilling one row of not metallized air-vias on both sides of the microstrip line with taper form. Fig. 2 presents the transition between microstrip and SIW. In this figure the configuration ends with regular waveguide. Fig. 2(a) presents the transition without air-vias on both sides of the microstrip line. The new microstrip-SIW transition with not metallized air-vias is presented in Fig. 2(b) and (c). In this figure, $a_{S I W}$ is the SIW width, $W_{\text {equi }}$ is the equivalent width, $d$ is the diameter of vias, $p$ is the vias inter-distance, $w_{t}$ is the width of taper form, $w_{m}$ is the width of the microstrip line, and $l_{t}$ is the length of taper form. In this study, two structures have been investigated. In the first one, the substrate is made of RT/duroid 6002 with electric permittivity $\varepsilon_{r}=2.94$, loss tangent of 0.0012. In the second structure, the dielectric is chosen as Rogers RO3003 with $\varepsilon_{r}=3$, loss tangent of 0.0013 , and the substrate height is $h=0.508 \mathrm{~mm}$ for both taper-via transitions and taper not metallized airvias transition.

Because the fields in the microstrip line are concentrated near the line, only one row of air-vias is needed on both sides of the microstrip. Comparing to the other microstrip transitions, the advantage of 
this new structure, is that there is better field matching between the SIW and micosrtip due to the confinement of the fields around the microstrip line. In order to validate this configuration we compare with taper transition without air-vias proposed in [9]. The structure consists of SIW substrate with ten metallized vias and thirteen not metallized air-vias at the both sides of the microstrip line. The width of SIW is obtained directly from [12], and the effective width can be calculated as:

$$
W_{\text {equi }}=\frac{c}{2 f_{c} \sqrt{\varepsilon_{r}}}
$$

Where $c$ is the speed of light, $f_{c}$ is the cutoff frequency and $\varepsilon_{r}$ is the relative permittivity of the substrate.
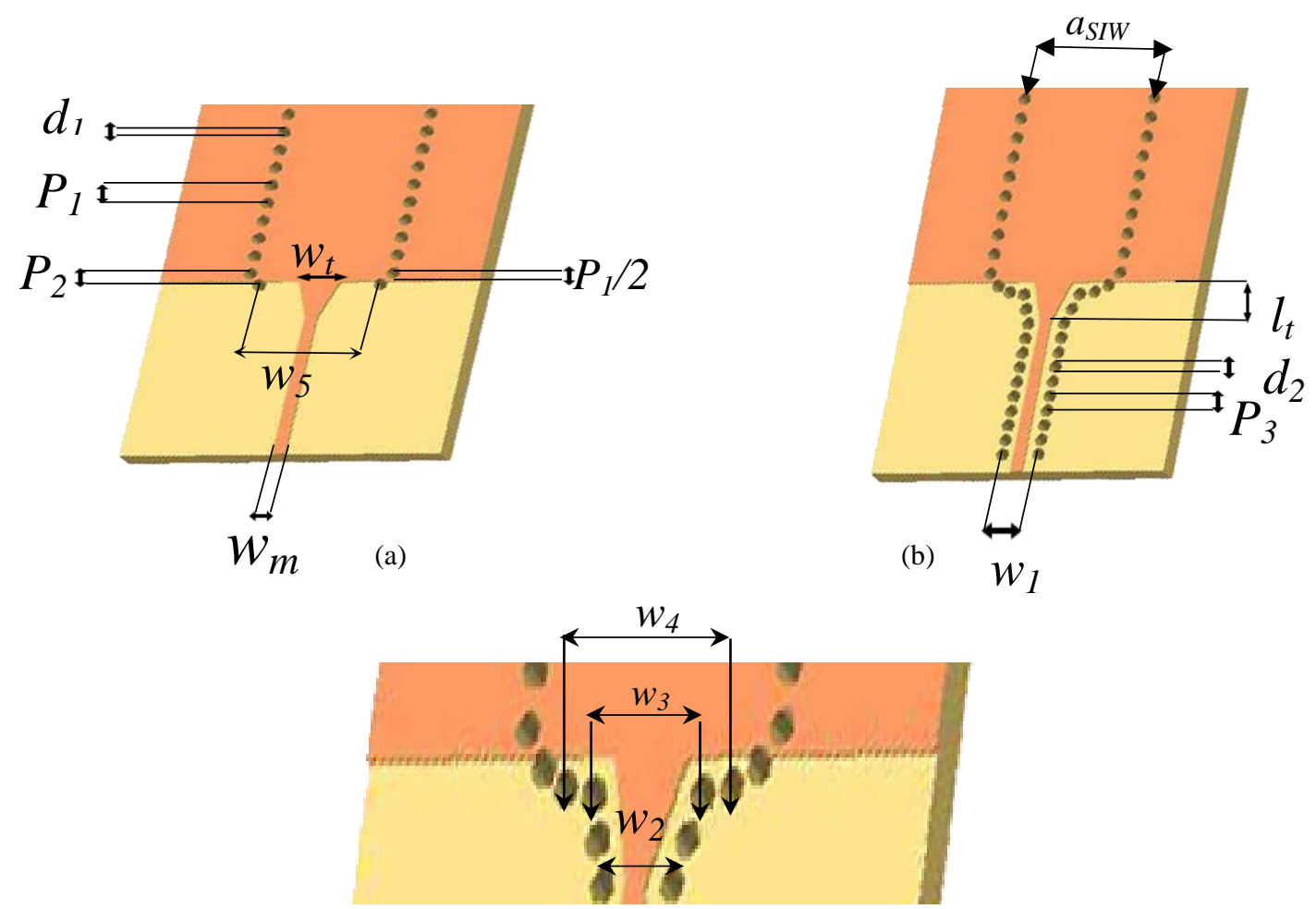

(c)

Fig. 2.Structural parameters of the proposed transition between microstrip and SIW

(a) Structure parameters of taper transition without Air-vias.

(b), (c) Structure parameters of taper transition with Air-vias.

\section{RESULTS AND DISCUSSION}

The simulations were carried out using commercial electromagnetic simulator: Ansoft HFSS. In the first structure, the final parameters of the simulated proposed transition are presented in table.1. Theoritically, The transition between microstrip line and SIW is much better when the return loss is low; which is achieved by having a good match between the microstrip and SIW in the fields and impedance. In order to do that, we have to maintain the greatest value of the fields on both sides of the microstrip. Fig. 3 . Shows $\mathrm{E}$ and $\mathrm{H}$ fields distribution in the transition for (a) the proposed taper air-via transition and (b) the conventional taper via transition, where the incident wave has been chosen with the same phase. 
From this comparaison, we notice that the fields are better confined when adding the air-vias on both sides of the microstrip line which lead to a best transition with SIW. Fig. 4 shows the comparison between the simulated S parameters of the proposed transition and those from [9] in Ku-band frequency. After the optimization in the parameters of the transition, in the simulation results we can see that the insertion loss is lower than $0.16 \mathrm{~dB}$ for taper-vias transition [9] and lower than 0.15 for the proposed transition in the entire Ku-band (12.4-18 GHz), from Fig. 4(a). About the return loss in fig. 4(b), the results show that the return loss is higher than $35 \mathrm{~dB}$ for taper-vias transition [9] and higher $41 \mathrm{~dB}$ for the proposed air-vias transition.

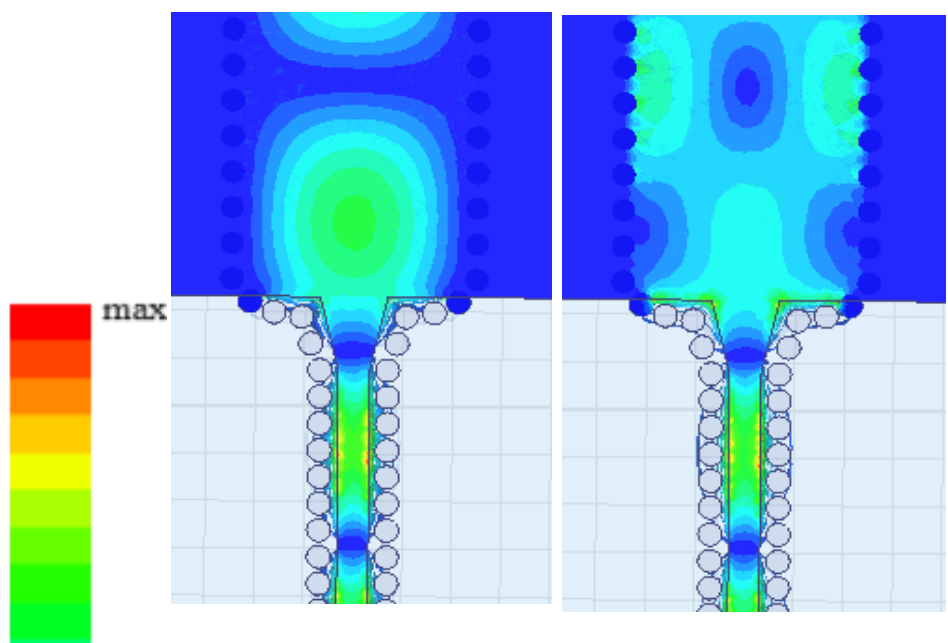
E- field
(a)
$\mathrm{H}$ - field

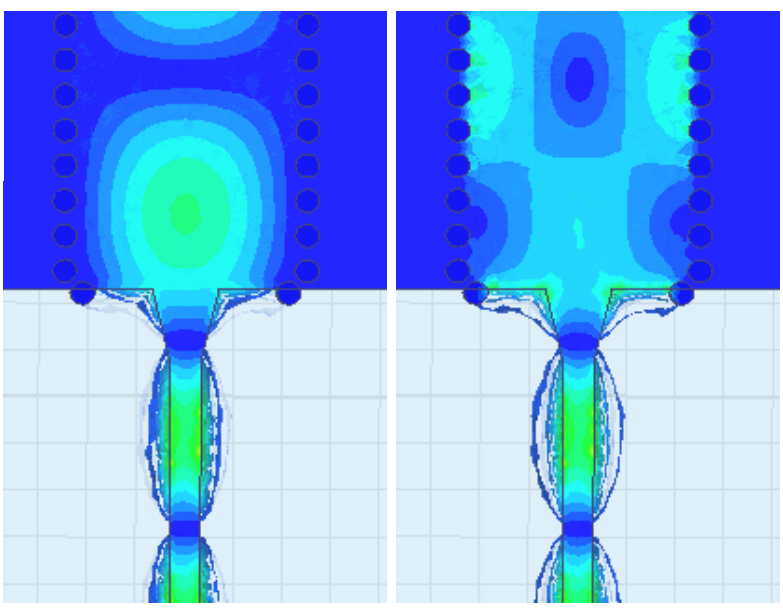

E- field

(b)

H- field

Fig. 3. E and $\mathrm{H}$ fields distribution in the transitions :

(a) proposed taper air-via transition;

(b) conventional taper via transition. 
Table 1: Parameters dimensions for the first structure.

\begin{tabular}{|c|c|c|c|c|}
\hline$f_{\mathrm{c}}(\mathrm{GHz})$ & $a_{S I W}(\mathrm{~mm})$ & $l_{t}(\mathrm{~mm})$ & $d_{l}(\mathrm{~mm})$ & $d_{2}(\mathrm{~mm})$ \\
\hline 9.488 & 9.9502 & 3.1 & 0.975 & 0.97 \\
\hline$P_{l}(\mathrm{~mm})$ & $P_{2}(\mathrm{~mm})$ & $P_{3}(\mathrm{~mm})$ & $w_{m}(\mathrm{~mm})$ & $w_{t}(\mathrm{~mm})$ \\
\hline 1.5 & 0.9494 & 1.125 & 1.2754 & 2.7533 \\
\hline$w_{l}(\mathrm{~mm})$ & $w_{2}(\mathrm{~mm})$ & $w_{3}(\mathrm{~mm})$ & $w_{4}(\mathrm{~mm})$ & $w_{5}(\mathrm{~mm})$ \\
\hline 2.75 & 3.5 & 4.25 & 6.5 & 8.4486 \\
\hline
\end{tabular}

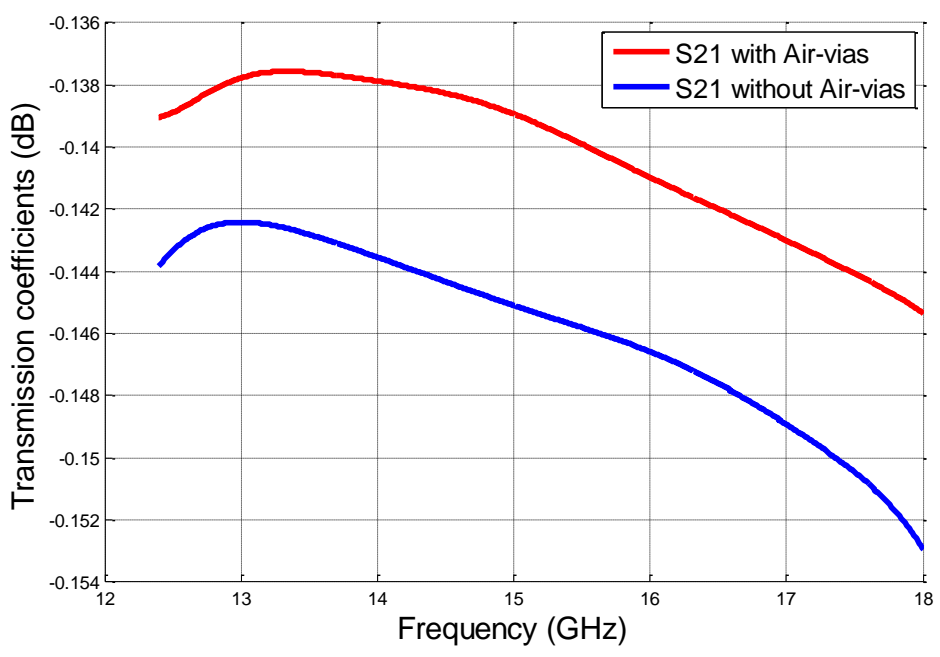

(a)

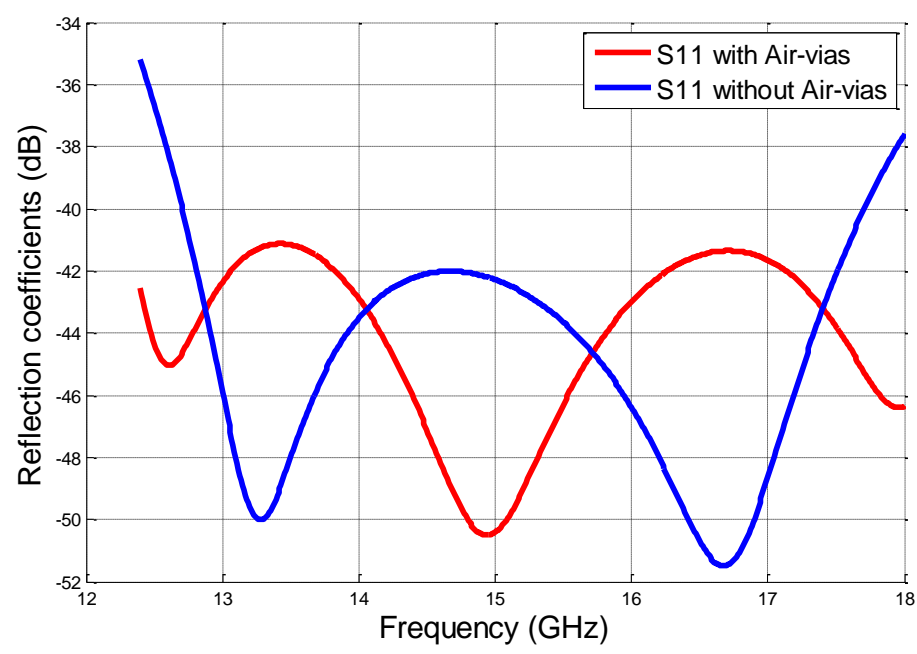

(b)

Fig. 4. S-parameters of the Transition micorstiop to SIW. (a) Transmission coefficients ; (b) Reflection coefficients

In the second structure, some parameters have changed and presented in the table.2. Two holes from both sides of the microstrip that have a distance $w_{4}$ between them were removed, (Fig.2.c) and the substrate is chosen as Rogers RO3003 with $\varepsilon_{r}=3$. Fig. 5 shows the comparison between the simulated $\mathrm{S}$ parameters of the proposed transition and the taper-via transition in Ku-band frequency. From Fig. 5(a), we can see that the insertion loss is lower than $0.17 \mathrm{~dB}$ for taper-via transition and lower than 0.16 for the proposed transition. in Fig. $5(\mathrm{~b})$, the return loss is higher than $33 \mathrm{~dB}$ for taper-via transition, and higher than $40 \mathrm{~dB}$ for the proposed air-via transition.

Table 2: Parameters dimensions for the second structure

\begin{tabular}{|r|r|r|r|r|r|r|}
\hline$f_{\mathrm{c}}(\mathrm{GHz})$ & $a_{S I W}(\mathrm{~mm}$ & $l_{t}(\mathrm{~mm})$ & $d_{l}(\mathrm{~mm})$ & $d_{2}(\mathrm{~mm})$ & $P_{l}(\mathrm{~mm})$ & $P_{2}(\mathrm{~mm})$ \\
\hline 9.488 & 7.95 & 3.1 & 0.975 & 0.94 & 1.5 & 0.9494 \\
\hline$P_{3}(\mathrm{~mm})$ & $w_{\mathrm{m}}(\mathrm{mm})$ & $w_{\mathrm{t}}(\mathrm{mm})$ & $w_{1}(\mathrm{~mm})$ & $w_{2}(\mathrm{~mm})$ & $w_{3}(\mathrm{~mm})$ & $w_{5}(\mathrm{~mm})$ \\
\hline 1.125 & 1.2754 & 2.7533 & 2.75 & 3.5 & 4.25 & 6.4484 \\
\hline
\end{tabular}




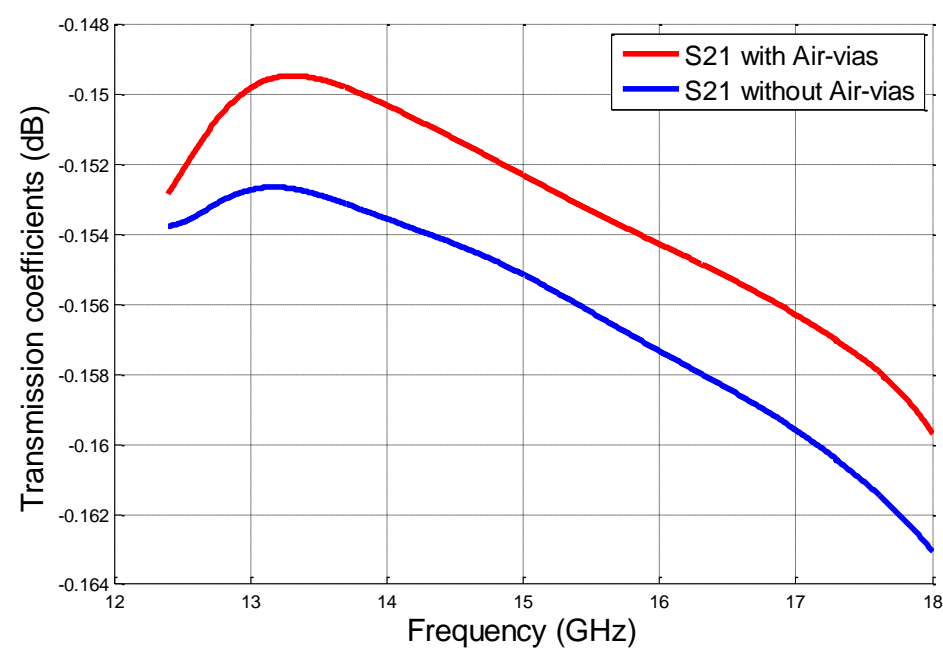

(a)

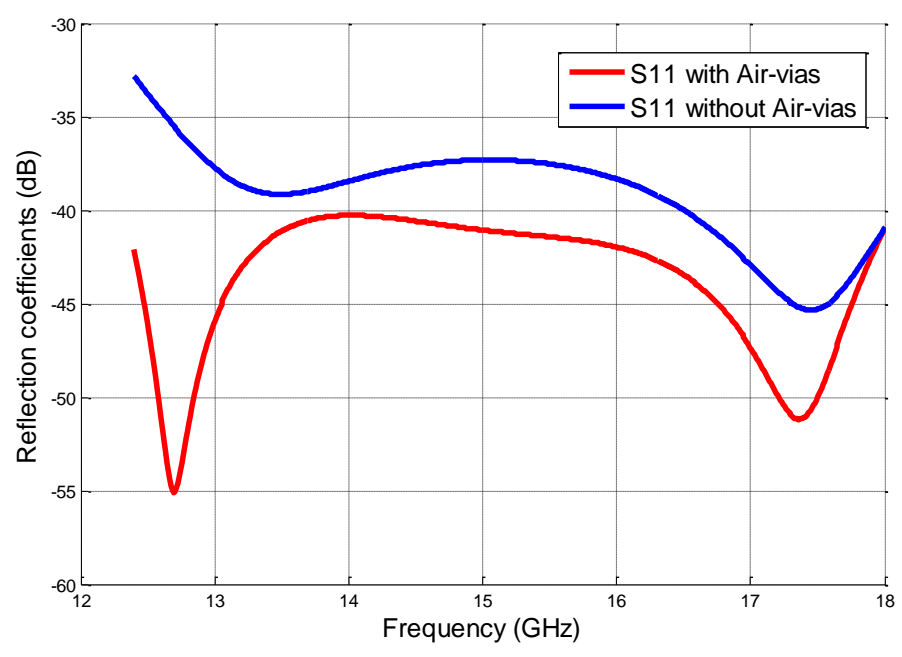

(b)

Fig. 5. S-parameters of the Transition micorstiop to SIW. (a)Transmission coefficients ; (b) Reflection coefficients

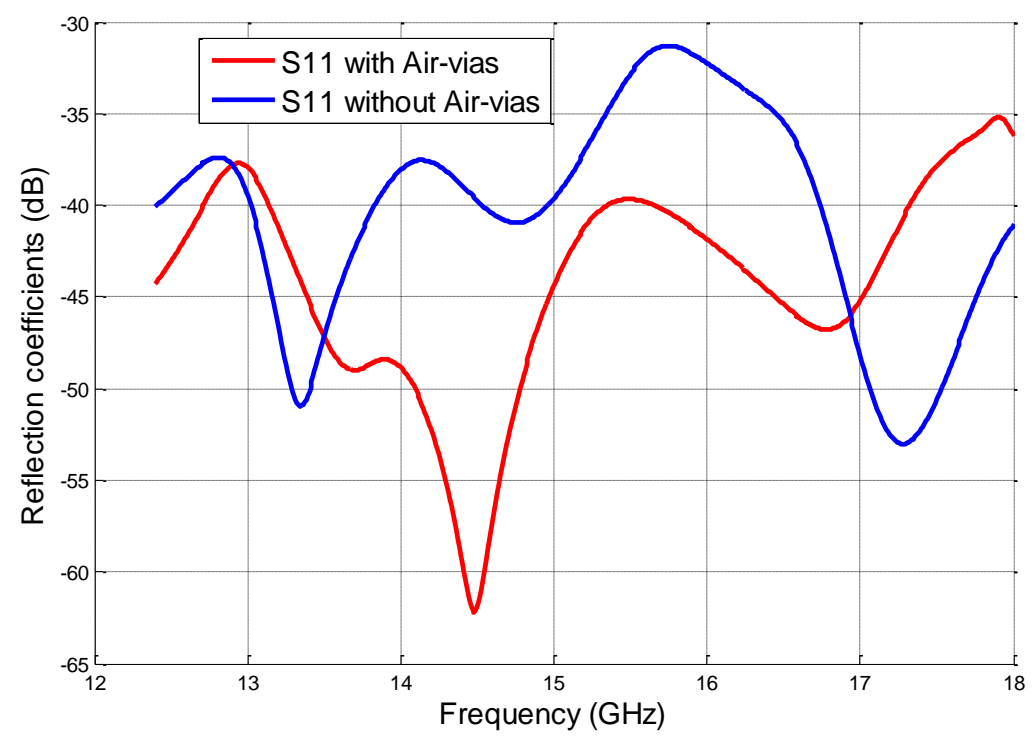

Fig. 6. Reflection coefficients of back-to-back transition micorstiop to SIW for the second example

In this structure, back-to-back transition is simulated for conventional taper-via and taper with air-vias. Fig. 6 presents the comparison between the simulated S parameters of the two transitions. We can see that the return loss is higher than $31 \mathrm{~dB}$ for taper-via transition, and higher than $35 \mathrm{~dB}$ for the proposed air-via transition, in the entire Ku-band $(12.4-18 \mathrm{GHz})$.

In order to validate the simulated results, an experimental prototype of the proposed back-to-back transition with air-vias was fabricated (Fig. 7), where the substrate made of RT/duroid 6002 and the parameters used are presented in table 1. Because of drill size restrictions, the simulation via diameter (cf. Table 1) was changed for $d_{l}$ and $d_{2}$ to $0.95 \mathrm{~mm}$. Fig. 8 presents the comparison between the simulated and measured results of the new transition with not metalized air-vias and we can see that the simulation results are in good agreement with the measurements. From Fig.8 (a), in the Ku-band frequency (12.4$18 \mathrm{GHz}$ ), the proposed transition shows that the return loss is higher than $35 \mathrm{~dB}$ for the simulated results 
and higher than $29 \mathrm{~dB}$ for the measured results whereas in Fig.8 (b) the simulated results of the insertion loss is lower than $0.68 \mathrm{~dB}$ and about 0.685 for the measured results.

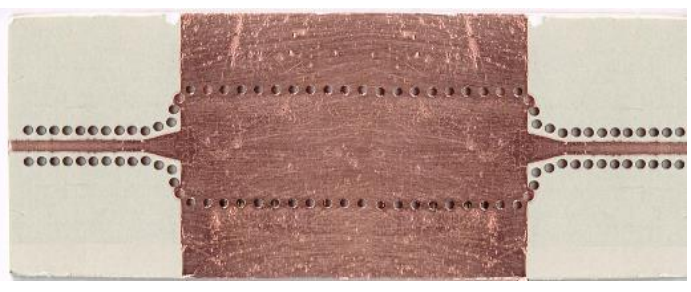

(a)

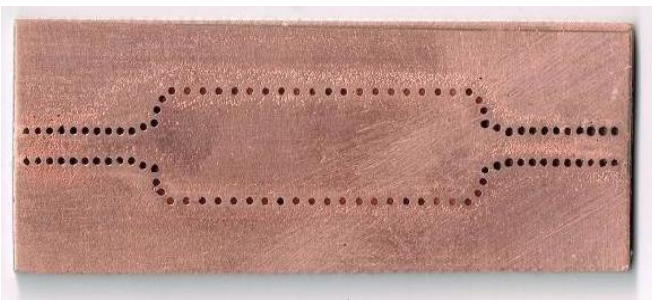

(b)

Fig. 7. The proposed transition prototype

(a) Front side; (b) Back side.

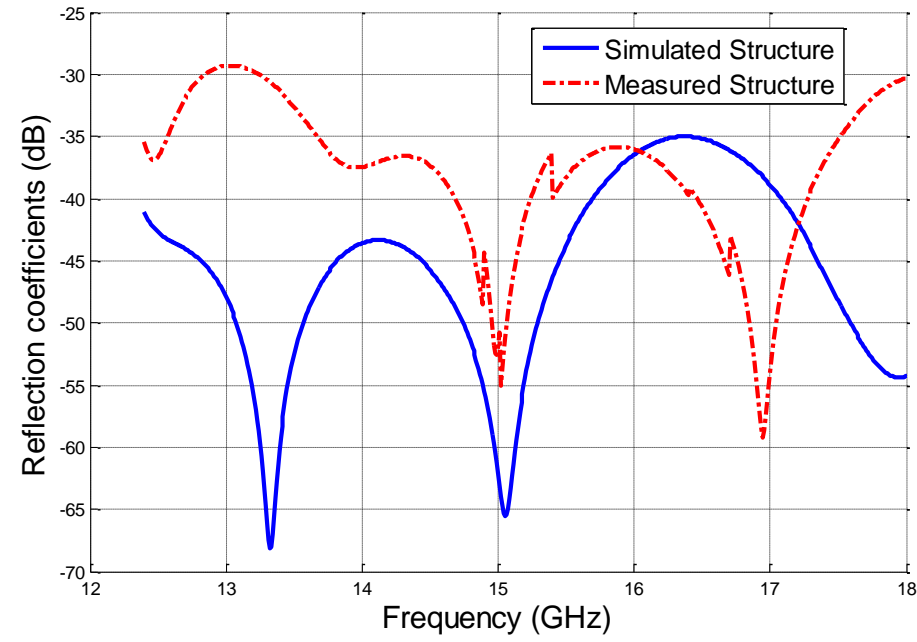

(a)

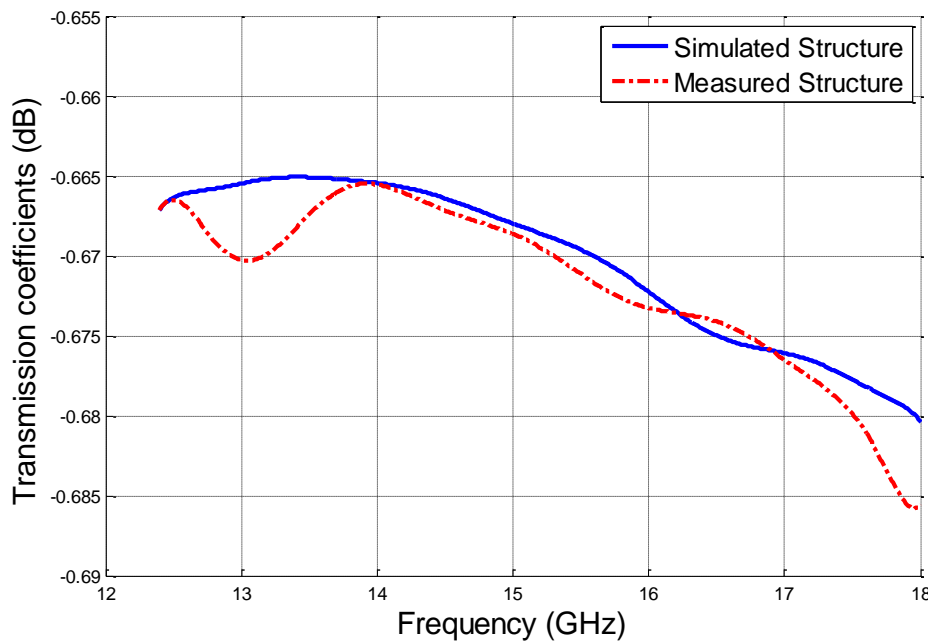

(b)

Fig. 8. S parameter of the proposed transition. (a) Reflection coefficients ; (b) Transmission coefficients

\section{CONCLUSION}

In this letter, a new transition microstrip to substrate integrated waveguide at $\mathrm{Ku}$-band frequency is proposed and designed. The back-to-back transition has also been fabricated to confirm the proposed transition. Simulations results show that the return loss values is around $41 \mathrm{~dB}$ over Ku-band frequency. For the experimental prototype of the back-to-back design, the measured results are in good agreement with the simulation results, and show that the return loss is better than $35 \mathrm{~dB}$ for the simulated results and higher than $29 \mathrm{~dB}$ for the measured results in $\mathrm{Ku}$ band frequency. This new transition with air-vias can give a good platform for RF/microwave circuits and systems development.

\section{ACKNOWLEDGMENT}

This work was supported by the laboratory of electromagnetic and telecommunication, University of Constantine 01, Route Ain El Bey, 25000, Constantine, Algeria. 


\section{REFERENCES}

[1] D. Deslandes, K. Wu, "Integrated microstrip and rectangular waveguide in planar form," IEEE Microwave and Wireless Components Letters, VOL. 11, NO. 02, 68-70, 2001.

[2] H. Nam, T.-S. Yun, K.-B. Kim, K.-C. Yoon, J.-C. Lee, "Ku-band transition between microstrip and substrate integrated waveguide (SIW)," Asia-Pacific Microwave Conference Proceedings (APMC), VOL. 1, 1-4, 2005.

[3] T. H. Yang, C. F. Chen, T. Y. Huang, C. L. Wang, R. B. Wu, "A 60GHz LTCC transition between microstrip line and substrate integrated waveguide," Asia-Pacific Microwave Conference Proceedings (APMC), VOL. 1, 4-7, 2005.

[4] Y. Ding, K. Wu, "Substrate integrated waveguide-to-microstrip transition in multilayer substrate," IEEE Transactions on Microwave Theory and Techniques, VOL. 55, NO. 12, 2839-2844, 2007.

[5] Z. Sotoodeh, B. Biglarbegian, F. H. Kashani, H. Ameri, "A novel bandpass waveguide filter structure on SIW technology," Progress In Electromagnetics Research Letters, PIER., 2, 141-148, 2008.

[6] F. Bauer, W. Menzel, "A wideband transition from substrate integrated waveguide to differential microstrip lines in multilayer substrates," 40th European Microwave Conference (EuMC), 811-813, 2010.

[7] D.-K. Cho, H.-Y. Lee, “A new broadband microstrip-to-SIW transition using parallel HMSIW,” Journal of Electromagnetic Engineering And Science, VOL. 12, NO. 2, 171-175, 2012.

[8] E. D. Caballero, A. B. Martinez, H. E. Gonzalez, O. M. Belda, V. B. Esbert, "A novel transition from microstrip to a substrate integrated waveguide with higher characteristic impedance," IEEE MTT-S International Microwave Symposium Digest (IMS), 1-4, 2013.

[9] Z. Kordiboroujeni and J. Bornemann, "New wideband transition from microstrip line to substrate integrated waveguide," IEEE Transactions on Microwave Theory and Techniques, VOL. 62, NO.12, 2983-2989, 2014.

[10] D. M. Pozar, "Microwave Engineering," 3rd Ed. John Wiley \& Sons, 2011.

[11] D. Deslandes, "Design equations for tapered microstrip-to-Substrate Integrated Waveguide transitions," IEEE MTT-S International Microwave Symposium Digest, 704-707, 2010.

[12] Z. Kordiboroujeni and J. Bornemann, "Designing the width of substrate integrated waveguide structures," IEEE Microwave and Wireless Components Letters, VOL. 23, NO. 10, 518-520, 2013. 